\title{
Survival of Spinal Metastasis Disease based on Immunohistochemistry Subtype of Breast Cancer: A Systematic Review and Meta-analysis
}

\author{
Ivan Hugo Hadisaputra ${ }^{1}$, Tjokorda Gde Bagus Mahadewa ${ }^{2 *}$, Putu Eka Mardhika $^{2}$ \\ ${ }^{1}$ Department of Surgery, Faculty of Medicine, Universitas Udayana, Sanglah General Hospital, Bali, Indonesia; ${ }^{2}$ Department of \\ Surgery, Division of Neurosurgery, Faculty of Medicine, Universitas Udayana, Sanglah General Hospital, Bali, Indonesia
}

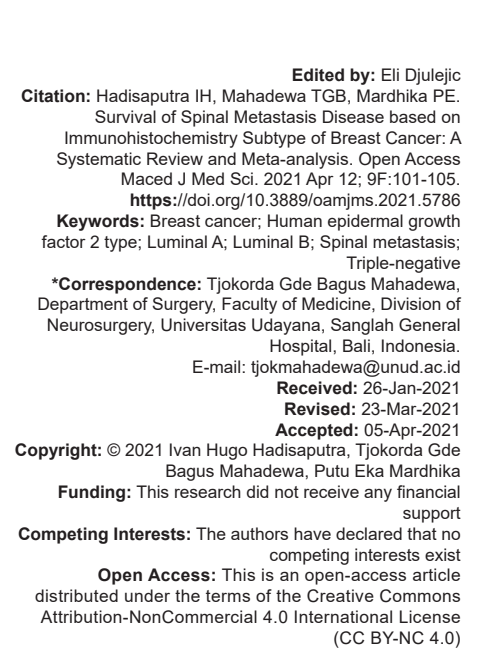

Abstract

BACKGROUND: Breast cancer is categorized as a slow-growth tumor in the spinal metastases disease (SMD) scoring system. Based on immunohistochemistry, breast cancer has four subtypes: Luminal A (LumA), luminal B (LumB), human epidermal growth factor 2 (Her-2) type, and triple-negative breast cancer (TNBC). TNBC has the poorest prognosis.

AIM: This study aimed to describe the survival time of breast cancer with SMD based on immunohistochemistry subtypes through systematic review and meta-analysis.

METHODS: This is a systematic review and meta-analysis study. This study used electronic articles published in PubMed and CENTRAL online database. We used keywords ([breast] AND [cancer] AND [spine] AND [metastasis]) to find eligible studies. Articles included were full-text studies in English. Survival time as the outcome was pooled according to the immunohistochemistry subtype of breast cancer. Statistical analysis was performed using software Stata.

RESULTS: Five articles met our inclusion and exclusion criteria. LumA, LumB, Her-2 type, and TNBC have a survival time of 32.84 months, 35.20 months, 60.8 months, and 14.27 months, respectively.

CONCLUSION: TNBC has the lowest survival time in the pooled analysis. We proposed TNBC be categorized as a moderate growth primary tumor.

\section{Introduction}

Breast cancer is one of the most common cancers to metastasize to the spine and is the second leading cause of death in women associated with cancer [1]. Spinal metastasis is a significant cause of severe morbidity and decreasing quality of life due to severe pain, pathological fractures, spinal cord compression, and hypercalcemia [2]. Patients with spinal metastases have short remaining life; thus, over-treatment is a concern. Therefore, treatments are focusing on symptoms and the expected quality of life or survival [3], [4].

As many as, $20-30 \%$ of breast cancers will be metastasized, of which $9.7 \%$ cases are to the spine. The diagnosis can be delayed up to 2 months from the moment a patient comes to the doctor for the $1^{\text {st }}$ time [5], [6]. Patients diagnosed with spinal metastases shows spinal pain as a symptom in $63.3 \%$, and neurological deficits are seen in only $1.4 \%$ of cases [7].
Breast cancer has four phenotypes that play an essential role in routine clinical management: Luminal A (LumA), luminal B (LumB), human epidermal growth factor 2 (Her-2) positive, and basal-like/triplenegative breast cancer (TNBC). These phenotypes are assessed based on immunohistochemical pathological markers consisted of estrogen receptor, progesterone receptor, and Her-2 [1], [8]. Positive hormone receptor breast cancer has the best prognostic with the lowest relapse rate, whereas negative hormone receptor is associated with poor survival outcome [6].

Several scoring systems can predict spinal metastases patient's survival, for example, Tokuhashi et al., Tomita et al., Bauer and Wedin, Van der Linden et al., and Katagiri et al. These scoring systems can determine the preoperative evaluation of the prognostic spinal metastases but do not differentiate breast cancer phenotype itself [9], [10], [11], [12], [13], [14]. This study aimed to evaluate every subtype of breast cancer's nature according to patients' survival with spinal metastases. 


\section{Methods}

\section{Eligibility criteria}

This review included all studies of spine metastases of breast cancer with immunohistochemistry results. We included all publications in English. However, articles in other languages were translated using Google translate and decided by the author to be included. The outcome of interest in this review was the survival time (month) of each subtype of breast cancer in spinal metastasis patients.

\section{Search strategy}

In this study, we used keywords ([breast] AND [cancer] AND [spine] AND [metastasis]) in online databases to find eligible studies. The study selection process was performed by two authors $(\mathrm{IHH}$ and PEM) to reduce the possibility of discarding relevant studies. The decision of another author (TGBM) was used when disagreement occurred. Duplicate records were removed. Titles and abstracts were screened, and irrelevant studies were removed. Studies that passed the first screening were further evaluated to comply with the inclusion and exclusion criteria of this review. Finally, the studies were further evaluated for their quality before included in this review.

\section{Data collection process}

An electronic data collection form was used to collect data by each author. The collected data by each author will be merged and be managed with software Stata.

\section{Data items}

The data items were the author's name, year of publication, method, sample size, diagnosis of participant, age, immunohistochemistry profile of breast cancer, and survival time (months). They were pooled and analyzed.

\section{Assessment of quality of study}

Studies that complied with inclusion and exclusion criteria were assessed for their quality to ensure the studies' validity and reliability. This process was done independently by two authors using a standardized critical appraisal tool to minimize the possibility of bias in study selection. The critical appraisal tool was Joanna Briggs Institute (JBI) critical appraisal tool based on study design. The decision of the third author was used when disagreement occurred.

A cutoff point was used to determine the quality of the study. Cutoff point in this review was half of the total score in each JBI critical appraisal checklist. A low-quality study was defined as a score below the cutoff point while conversely was termed a high-quality study.

\section{Synthesis of result}

The outcome of interest was pooled and analyzed. Meta-analyses were performed using software Stata. The random effect model was used regardless of heterogeneity.

\section{Results}

We found five articles describing the survival time of different immunohistochemistry of spinal metastasis disease Table 1. Five articles described the survival time of TNBC, and only three articles described the survival time of LumA, Lum B, and Her-2 type Table 2. The study selection process according to the PRISMA flow diagram is shown in Figure 1.

\section{LumA}

There are three studies reporting survival time of subtype LumA spinal metastasis. The metaanalysis of survival of subtype LumA showed survival of 32.8 months $\left(95 \% \mathrm{Cl} 30.9-34.7 ; \mathrm{I}^{2}=92.5 \%\right)$. The forest plot is shown in Figure 2.

\section{LumB}

There are three studies reporting survival time of subtype LumB spinal metastasis. The metaanalysis of survival of subtype LumB showed survival of 35.2 months $\left(95 \% \mathrm{Cl} 29.5-40.9 ; \mathrm{I}^{2}=85.9 \%\right)$. The forest plot is shown in Figure 3.

\section{Her-2 type}

There are three studies reporting survival time of subtype Her-2 type spinal metastasis. The meta-analysis of survival of subtype Her-2 type showed survival of 60.85 months $(95 \% \mathrm{Cl} 53.4-68.3$; $\left.1^{2}=95.1 \%\right)$. The forest plot is shown in Figure 4 .

\section{TNBC}

There are five studies reporting survival time of subtype TNBC spinal metastasis. The metaanalysis of survival of subtype TNBC showed survival of 14.27 months $\left(95 \%\right.$ Cl $\left.12.4-16.15 ; I^{2}=91.3 \%\right)$. The forest plot is shown in Figure 5. 
Table 1: Summary of findings of included studies

\begin{tabular}{|c|c|c|c|c|}
\hline Study author & Type of study & Level of evidence & Participant & Outcome \\
\hline Amelot et al.,[15] 2020 & Prospective cohort & $2 \mathrm{~b}$ & Total 123; LumA 46; LumB 25; Her-2 type 23; TNBC 29 & $\begin{array}{l}\text { LumA } 35.6 \text { (7.5); LumB } 48.8 \text { (23.2); Her-2 } \\
\text { type } 76.1 \text { (21.5); TNBC } 17.4 \text { (6.2) }\end{array}$ \\
\hline Bollen et al.,[3] 2014 & Retrospective cohort & $2 b$ & Total 111; LumA 67; LumB 9; Her-2 type 11; TNBC 24 & $\begin{array}{l}\text { LumA } 22.5(17.9-27.0) \text {; LumB } 26.9(9.1-44.7) \text {; Her-2 } \\
\text { type } 20.9(1.1-40.8) ; \text { TNBC } 5.5(2.0-9.0)\end{array}$ \\
\hline Chan-Seng et al.,[4] 2014 & Retrospective cohort & $2 b$ & Total 140; LumA 67; LumB 16; Her-2 type 4; TNBC 12 & LumA 30.5; LumB 26.25; Her-2 type 22.25; TNBC 39 \\
\hline Tan et al.,[16] 2017 & Retrospective cohort & $2 b$ & $\begin{array}{l}\text { Total 185; ER (+) 51; ER (-) 0; PgR (+) 62; PgR (-) 1; } \\
\text { Her-2 (+) 100; Her-2 (-) 36; HR (+) 42; HR (-) 0; Not } \\
\text { triple (-) 161; Triple (-) } 24\end{array}$ & $\begin{array}{l}\text { ER (+) } 13(1-72) ; \text { PgR (+) } 15(1-80) ; \text { Her-2 (+) } \\
20 \text { (1-125); Her-2 (-) } 26.5(3-96) ; \text { HR (+) } 12(1-72) ; \\
\text { Not triple (-) } 30 \text { (1-204); Triple (-) } 11(1-27)\end{array}$ \\
\hline Wang et al.,[7] 2014 & Retrospective cohort & $2 b$ & $\begin{array}{l}\text { Total 151; ER (+) 96; ER (-) 16; PgR (+) 28; } \\
\text { PgR (-) 25; HR (+) 113; HR (-) 17; Her-2 (+) 22; } \\
\text { Her-2 (-) 49; TNBC } 8\end{array}$ & $\begin{array}{l}\text { ER (+) } 21.5 \text { (15.9-27); ER (-) 10.6 (1.3-33.3); PgR (+) } \\
\text { 18.8; PgR (-) 16.6 (10.6-27.1); HR (+) 21.5 (15.5-26.8); } \\
\text { HR (-) 10.6 (1.3-33.3); Her-2 (+) } 23.1(13.8-27.3) ; \\
\text { Her-2 (-) } 21.3(13.4-27) ; \text { TNBC } 9.9(1.1-46.8)\end{array}$ \\
\hline
\end{tabular}

Table 2: Characteristics of included studies

\begin{tabular}{|c|c|}
\hline Methods & Retrospective cohort \\
\hline \multirow{2}{*}{\multicolumn{2}{|c|}{$\begin{array}{c}\text { Survival in breast cancer patients with spine metastases: Prognostic assessment involving molecular markers (Amelot et al.,[15] 2020) } \\
\text { Inclusion criteria: }\end{array}$}} \\
\hline & \\
\hline Participants & $\begin{array}{l}\text { All consecutive patients treated for spinal metastases breast cancer; patients with spinal } \\
\text { metastases and breast cancer were synchronously diagnosed; patients with previously } \\
\text { diagnosed and treated breast cancer } \\
\text { Exclusion criteria: } \\
\text { Missing data or lost during the follow-up period }\end{array}$ \\
\hline Comparison & LumA 46; LumB 25; Her-2 type 23; TNBC 29 \\
\hline Outcome & Mean survival in months \\
\hline \multicolumn{2}{|c|}{ Molecular phenotype is associated with survival in breast cancer patients with spinal bone metastases (Bollen et al.., ${ }^{[3]} 2014$ ) } \\
\hline \multirow[t]{2}{*}{ Participants } & Inclusion criteria: \\
\hline & All consecutive breast cancer patients presenting with symptomatic spinal metastases \\
\hline Comparison & LumA 67; LumB 9; Her-2 type 11; TNBC 24 \\
\hline Outcome & Median survival in months \\
\hline \multicolumn{2}{|c|}{ Spinal metastases in breast cancer: Single center experience (Seng et al.,[4] 2017) } \\
\hline \multirow[t]{2}{*}{ Participant } & Inclusion criteria: \\
\hline & $\begin{array}{l}\text { Patients with spinal metastases from breast cancer; In asymptomatic patients }(35 \%) \text {, } \\
\text { spine metastases were diagnosed during systematic routine follow-up (bone } \\
\text { scintigraphy [single photon emission CT-CT], whole-body CT scan, or MRI) }\end{array}$ \\
\hline Comparison & LumA 67; LumB 16; Her-2 type 4; TNBC 12 \\
\hline Outcome & Mean survival in months \\
\hline \multicolumn{2}{|c|}{ Evaluation of prognostic factors and proposed changes to the modified Tokuhashi score in patients with spinal metastases from breast cancer (Tan et al.,[16] 2017) } \\
\hline \multirow[t]{4}{*}{ Participant } & Inclusion criteria: \\
\hline & $\begin{array}{l}\text { All cases of histologically-confirmed breast cancer spinal metastases patient who } \\
\text { presented }\end{array}$ \\
\hline & Exclusion criteria \\
\hline & Incomplete clinical/radiological findings or loss of follow-up with an unknown time of death \\
\hline Comparison & $\begin{array}{l}\text { ER (+) 51; ER (-) 0; PgR (+) 62; PgR (-) 1; Her-2 (+) 100; Her-2 (-) 36; HR (+) 42; } \\
\text { HR (-) 0; Not triple (-) 161; Triple (-) } 24\end{array}$ \\
\hline Outcome & Median survival in months \\
\hline \multicolumn{2}{|c|}{ Survival analysis of breast cancer subtypes in patients with spinal metastases (Wang et al.,[7] 2014) } \\
\hline \multirow[t]{2}{*}{ Participant } & Inclusion criteria: \\
\hline & $\begin{array}{l}\text { All patients with pathologically confirmed breast cancer with spinal metastases who had } \\
\text { undergone surgical treatment }\end{array}$ \\
\hline Comparison & $\begin{array}{l}\text { ER (+) 96; ER (-) 16; PgR (+) 28; PgR (-) 25; HR (+) 113; HR (-) 17; Her-2 (+) 22; } \\
\text { Her-2 (-) 49; TNBC } 8\end{array}$ \\
\hline Outcome & Median survival in months \\
\hline
\end{tabular}

\section{Discussion}

Prognostic scoring systems were designed to assist the practitioner during the decision-making process, whether a patient should be offered surgical treatment or not [17]. Based on immunohistochemistry, breast cancer was divided into four subtypes. In this study, the Her-2 type has the most extended survival with a surprising 60.8 months of survival time. LumA and B subtypes have similar survival with 32 and 35 months of life expectancy, respectively. Meanwhile, TNBC showed the shortest survival with 14 months of life expectancy.

According to Tokuhashi et al., 0 points are given to the primary lesion with survival found to be $<6$ months, and 5 points are given to the primary lesion with a survival of more than 1 year [10]. In this study, we found 14 months of life expectancy in spinal metastases with the TNBC subtype. Considering the survival is $<1$ year on the three studies by Foerster et al., Tan et al., and Wang et al.; 6.7 months, 11 months, and 9.9 months, respectively, we propose to include TNBC as primary lesion to point three or moderate growth in another scoring system.

TNBC is a poor prognostic factor; one reason is there is no specific targeted therapy available for TNBC [18]. The heterogeneity of detection of spinal metastasis was found in the studies included in this meta-analysis (Table 2). Studies in the center that routinely perform systematic follow-up (bone scintigraphy [single photon emission CT-CT], whole-body CT scan, or MRI) will detect spinal metastases faster than the other, thus makes survival seems longer.

Another consideration should be taken about the treatment provided in every study. The ideal management of spinal metastases breast cancer consisted of multiple aspects of specialties, including surgical oncology, spine surgery, medical oncology, radiation, pain management, and rehabilitation [19]. There is no clear distinction between what modalities of therapy given in the studies 


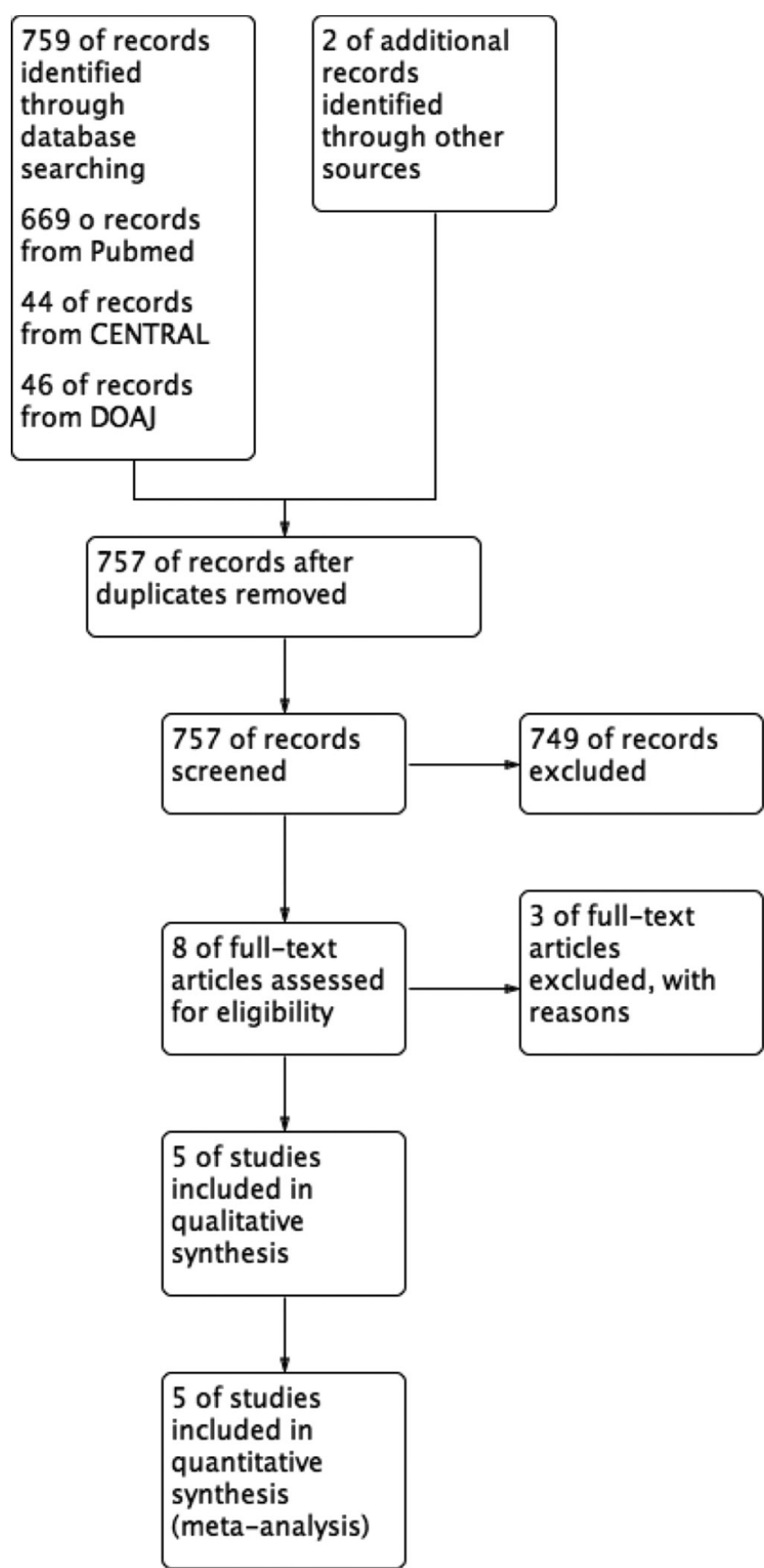

Figure 1: PRISMA flow diagram

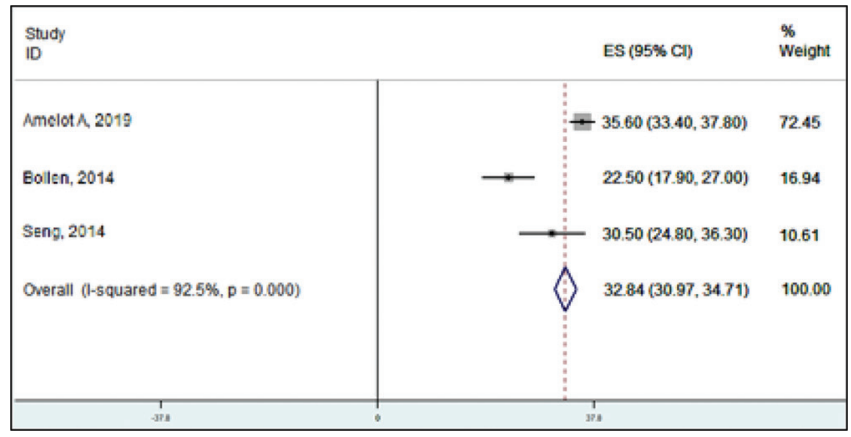

Figure 2: Forest plot of survival time of spinal metastasis disease with subtype luminal $A$

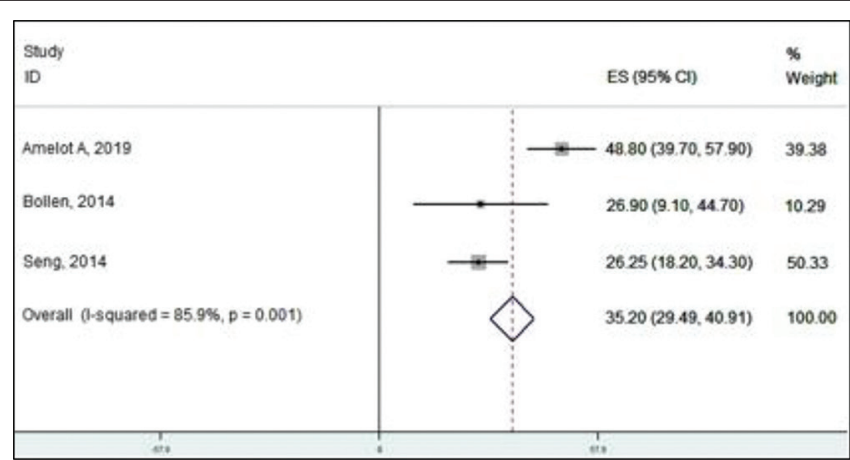

Figure 3: Forest plot of survival time of spinal metastasis disease with subtype luminal $B$

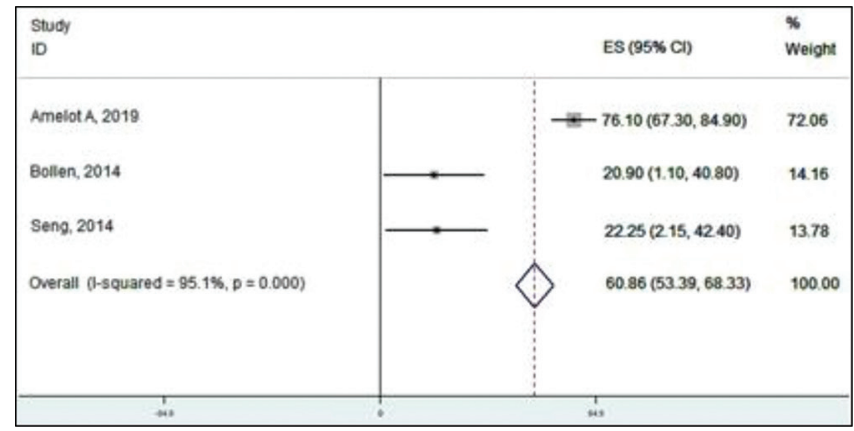

Figure 4: Forest plot of survival time of spinal metastasis disease with subtype human epidermal growth factor 2 type

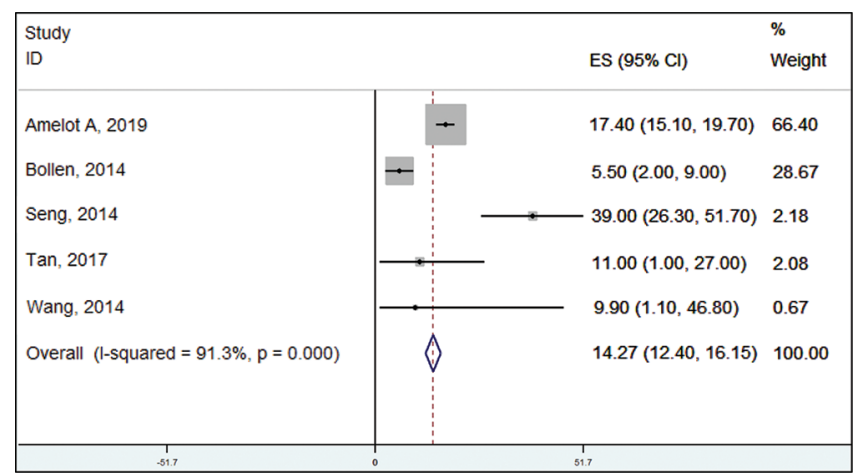

Figure 5: Forest plot of survival time of spinal metastasis disease with subtype triple-negative breast cancer

were analyzed. Zadnik et al. stated that dual therapy (chemotherapy and radiotherapy) was associated with significantly higher survival than single modality postoperative adjuvant therapy $(p=0.042)[20]$.

\section{Conclusion}

Eachbreastcancerwithitsimmunohistochemistry subtype has a different survival on patients with spinal metastases. Aggressive treatment can be performed in the patient with long-term survival. Meanwhile, we should reconsider subtype TNBC due to its aggressiveness and unavailability of targeted treatment. We proposed TNBC 
should be categorized as a moderate growth tumor in the metastasis scoring system.

\section{Author Contribution}

All authors contributed to the study's conception and design. Material preparation, data collection, and analysis were performed by Tjokorda Mahadewa, Ivan Hugo Hadisaputra, and Putu Eka Mardhika. Tjokorda Mahadewa acted as a decision-maker during the screening of articles. Tjokorda Mahadewa wrote the first draft of the manuscript and all authors commented on the previous versions of the manuscript. All authors read and approved the final manuscript.

\section{References}

1. Adler D, Pepke W, Akbar M. Operative treatment of metastatic breast cancer in the spine with regard to molecular phenotypes. J Cancer Metastasis Treat. 2019;5:45. https://doi. org/10.20517/2394-4722.2019.03

2. Foerster R, Bruckner T, Bostel T, Schlampp I, Debus J, Rief H. Prognostic factors for survival of women with unstable spinal bone metastases from breast cancer. Radiat Oncol. 2015;10:144. https://doi.org/10.1186/s13014-015-0458-9 PMid:26169373

3. Bollen L, Wibmer C, Wang M, van der Linden YM, Leithner $A$, Bunger CE, et al. Molecular phenotype is associated with survival in breast cancer patients with spinal bone metastases. Clin Exp Metastasis. 2015;32(1):1-5. https://doi.org/10.1007/ s10585-014-9685-y

PMid:25359620

4. Chan-Seng E, Charissoux M, Larbi A, Tetreau R, Gerber YN Verbizier-Lonjon DD, et al. Spinal metastases in breast cancer: Single center experience. World Neurosurg. 2014;82(6):1344-50. https://doi.org/10.1016/j.wneu.2014.08.010 PMid:25118060

5. Ju DG, Yurter A, Gokaslan ZL, Sciubba DM. Diagnosis and surgical management of breast cancer metastatic to the spine. World J Clin Oncol. 2014;5(3):263-71. PMid:25114843

6. Lin J, Goldstein L, Nesbit A, Chen MY. Influence of hormone receptor status on spinal metastatic lesions in patients with breast cancer. World Neurosurg. 2016;85:42-8. https://doi. org/10.1016/j.wneu.2015.07.068

PMid:26260940

7. Wang M, Jensen AB, Morgen SS, Wu CS, Sun M, Li H, et al Survival analysis of breast cancer subtypes in patients with spinal metastases. Spine (Phila Pa 1976). 2014;39(19):1620-7. https://doi.org/10.1097/brs.0000000000000473

PMid:24979144

8. Blows FM, Driver KE, Schmidt MK, Broeks A, van Leeuwen FE, Wesseling $\mathrm{J}$, et al. Subtyping of breast cancer by immunohistochemistry to investigate a relationship between subtype and short and long term survival: A collaborative analysis of data for 10, 159 cases from 12 studies. PLoS
Med. 2010;7(5):e1000279. https://doi.org/10.1371/journal. pmed.1000279

PMid:20520800

9. Tokuhashi $Y$, Uei H, Oshima M, Ajiro Y. Scoring system for prediction of metastatic spine tumor prognosis. World J Orthop. 2014;5(3):262-71. https://doi.org/10.5312/wjo.v5.i3.262 PMid:25035829

10. Tokuhashi Y, Matsuzaki H, Oda H, Oshima M, Ryu J. A revised scoring system for preoperative evaluation of metastatic spine tumor prognosis. Spine (Phila Pa 1976). 2005;30(19):2186-91. https://doi.org/10.1097/01.brs.0000180401.06919.a5 PMid:16205345

11. Tomita K, Kawahara N, Kobayashi T, Yoshida A, Murakami H, Akamaru T. Surgical strategy for spinal metastases. Spine (Phila Pa 1976). 2001;26(3):298-306. https://doi. org/10.1097/00007632-200102010-00016 PMid: 11224867

12. Bauer $\mathrm{HC}$, Wedin R. Survival after surgery for spinal and extremity metastases. Prognostication in 241 patients. Acta Orthop Scand. 1995;66(2):143-6. https://doi.org/10.3109/17453679508995508 PMid:7740944

13. van der Linden YM, Dijkstra SP, Vonk EJ, Marijnen CA, Leer JW Prediction of survival in patients with metastases in the spinal column: Results based on a randomized trial of radiotherapy. Cancer. 2005;103(2):320-8. https://doi.org/10.1002/cncr.20756 PMid: 15593360

14. Katagiri H, Takahashi M, WakaiK, Sugiura H, KataokaT, Nakanishi K. Prognostic factors and a scoring system for patients with skeletal metastasis. J Bone Joint Surg Br. 2005;87(5):698-703. https://doi.org/10.1302/0301-620x.87b5.15185 PMid: 15855375

15. AmelotA, TerrierLM, Cristini J, BuffenoirK, Pascal-Moussellard H, Carpentier A, et al. Survival in breast cancer patients with spine metastases: Prognostic assessment involving molecular markers. Eur J Surg Oncol. 2020;46(6):1021-7. https://doi. org/10.1016/j.ejso.2019.12.026

PMid:31899046

16. Tan KA, Tan JH, Zaw AS, Tan JY, Hey HW, Kumar N. Evaluation of prognostic factors and proposed changes to the modified Tokuhashi score in patients with spinal metastases from breast cancer. Spine (Phila Pa 1976). 2018;43(7):512-9. https://doi. org/10.1097/brs.0000000000002350 PMid:28749856

17. Morgen SS, Fruergaard S, Gehrchen M, Bjørck S Engelholm SA, Dahl B. A revision of the Tokuhashi revised score improves the prognostic ability in patients with metastatic spinal cord compression. J Cancer Res Clin Oncol. 2018;144(1):33-8. https://doi.org/10.1007/s00432-017-2519-y PMid:28986702

18. Wahba HA, El-Hadaad HA. Current approaches in treatment of triple-negative breast cancer. Cancer Biol Med. 2015;12(2):106-16.

PMid:26175926

19. Sciubba DM, Goodwin CR, Yurter A, Ju D, Gokaslan ZL, Fisher C, et al. A systematic review of clinical outcomes and prognostic factors for patients undergoing surgery for spinal metastases secondary to breast cancer. Global Spine J. 2016;6(5):482-96. https://doi.org/10.1055/s-0035-1554402 PMid:27433433

20. Zadnik PL, Hwang L, Ju DG, Groves ML, Sui J, Yurter A, et al. Prolonged survival following aggressive treatment for metastatic breast cancer in the spine. Clin Exp Metastasis. 2014;31(1):4755. https://doi.org/10.1007/s10585-013-9608-3

PMid:23999761 